\title{
Research on Two-Echelon Green Supply Chain Decision under Government Subsidy
}

\author{
Shilin Zhan, Zhengang Shu, Hao Jiang \\ School of Business and Administration, South China University of Technology, Guangzhou, China \\ Email: hbhgzsl@163.com
}

How to cite this paper: Zhan, S.L., Shu, Z.G. and Jiang, H. (2018) Research on Two-Echelon Green Supply Chain Decision under Government Subsidy. American Journal of Industrial and Business Management, 8, 487-495.

https://doi.org/10.4236/ajibm.2018.83032

Received: February 7, 2018

Accepted: March 6, 2018

Published: March 9, 2018

Copyright $\odot 2018$ by authors and Scientific Research Publishing Inc. This work is licensed under the Creative Commons Attribution International License (CC BY 4.0).

http://creativecommons.org/licenses/by/4.0/

\section{Open Access}

\begin{abstract}
With the background of government subsidies and increasing consumer environmental awareness, this article establishes a two-echelon supply chain model of manufacturer and retailer. Based on this model, this article analyzes the decision-making problems of manufacturer and retailer under both decentralized and centralized decision modes, and the impact of consumer green sensitivity on product pricing, green degree and other decisions. The results show that government subsidies, higher consumer green sensitivities are conducive to green product promotion and members of decentralized decision supply chain, but higher consumer green sensitivity will reduce the overall supply chain profit in a centralized decision mode. Finally, this paper discusses the design of supply chain contract mechanism in decentralized decision mode to achieve supply chain coordination.
\end{abstract}

\section{Keywords}

Green Product, Consumer Green Sensitivity, Game Decision, Supply Chain Coordination

\section{Introduction}

Since the Industrial Revolution, various industries experienced rapid development, and human's material life has been greatly facilitated and enriched, at the same time, people are confronted by the problems of resource shortage, environmental pollution, global warming and so on. Therefore, the development of green technology and promotion of green products have become particularly important. Governments all over the world have launched fiscal and taxation policies to promote the development of green technology and products. At the same time, under the influence of government regulations, market and public pressure, more and more enterprises actively formulate green strategy and 
promote the implementation of green technology and products.

The rest of the paper is organized as follows. Section 2 provides the background literature of this paper. Section 3 discusses the problem and model assumptions. Section 4 provides establishment and solution of the model. Section 5 discusses design of supply chain coordination mechanism. Section 6 presents the results of numerical analysis. Section 7 concludes with the discussion and future research directions.

\section{Literature Review}

Green supply chain management has been on the rise since 1990s. In the past ten years, more and more scholars have begun to pay attention to the research of green supply chain management. The research of Menges (2003) [1] shows that consumers buy green products not only because they are concerned about environmental protection, but also because buying green products can bring higher utility. Bowen (2001) [2] and Li Yina et al. (2011) [3] discuss in this paper about the relationship between enterprise green practice, supply chain management ability and enterprise performance under institutional pressure and green supply chain environment. Eriksson (2004) [4] points out by studying duopoly green market that when consumers do not voluntarily internalize external environment, public policies must be intervened in the form of subsidies and other forms to protect the environment. Zhu Qinghua et al. (2007) [5] and Cohen et al. (2015) [6] studied the game between government and enterprises and green product manufacturers in green supply chain. Conrad (2005) [7], Liu et al. (2012) [8] and Zhang et al. (2015) [9] established green supply chain model under various circumstances, and studied the influence of consumers' environmental protection consciousness on the decision making of members of supply chain. Mitra (2008) [10], Cohen et al. (2015) [11], Ling Liuyi et al. (2012) [12] researched the influence of different forms of government green subsidies and the best form of subsidy under different circumstances.

The above researches cover many aspects of green product supply chain management, including multi-game of green supply chain, the impact of consumer's awareness of environmental protection, government subsidies and so on. This paper further discusses the issues of decision making of manufacturers and retailers in the two-level supply chain of green products under the condition of government subsidies, as well as the influence of consumer's green sensitivity on product pricing, green degree and other decisions under the two modes of decentralized and centralized decision-making.

\section{Problem Description and Model Assumptions}

\subsection{Problem Description}

This paper considers a two-level supply chain system with government's participation, which consists of a manufacturer of green products and a retailer. The manufacturer produces green products and the retailer sells green products. And 
the government will subsidize manufacturers based on product's greenness and sales volume. The demand of customers for green products is not only related to the price, but also to the green degree of the product and the green sensitivity of consumers. The decision problem of manufacturers is to determine the green degree of green products and wholesale prices to maximize their own profits, and the decision problem of retailers is to determine the sales price of green products to maximize their own profits.

\subsection{Model Symbols and Assumptions}

The model symbols covered in this article are as follows, $p, w, c$ are the retail price of product, wholesale price and unit cost of production respectively. $\mathrm{D}$ stands for the demand of green product and $\theta$ is the green degree of green product; $\alpha$ is the sensitivity of consumers to green degree of product. $\pi_{r}, \pi_{m}$ represents the profits of retailers and manufacturers respectively.

The assumptions of this article are as followings:

- The market demand of green product is negatively correlated with price and positively correlated with green degree of product. The demand function is: $D=a-b p+\alpha \theta ;$

- In terms of production cost, the marginal production cost of green product is c. At the same time, manufacturers must invest in research and development of green technological innovation in the production of green products. According to the study of Savaskan (2006) [13] and Swami (2013) [14], it is assumed that the manufacturer's research and development investment in green technology innovation is proportional to the square of green degree, which is $\xi \theta^{2} / 2$.

\section{Establishment and Solution of the Model}

\subsection{Decision Making by Retailers and Manufacturers in Decentralized Decision-Making Mode}

Under the decentralized decision-making mode, this paper adopts the Stackelberg game model who takes the leading position of manufacturers, which means manufacturers and retailers are independent of each other and regard the maximum of their own profits as a decision goal. The manufacturer determines the green degree and wholesale price of the green product firstly, and then the retailer, as a follower of the supply chain, determines the retail price of the green product. The profit functions of retailers and manufacturers are as follows:

$$
\begin{aligned}
& \pi_{r}=(p-w) D=(p-w)(a-b p+\alpha \theta) \\
& \pi_{m}=(w-c+r \theta)(a-b p+\alpha \theta)-\beta \theta^{2}
\end{aligned}
$$

The reverse induction method is used to search for the best decision of retailers and manufacturers. By finding the first derivative of $p$ in function (1) and making it zero, the optimal pricing decision of the retailer can be obtained 
as follows:

$$
p_{d}^{*}=(a+\alpha \theta+b w) / 2 b
$$

By introducing function (3) of the optimal pricing decision for retailers into the manufacturer's profit function (2), the first derivative of and is obtained and make it as zero, and the optimal wholesale price and the best green degree decision are obtained, and the optimal pricing results of retailers can be obtained as follows:

$$
\begin{gathered}
w_{d}^{*}=\frac{b c+a}{2 b}+\frac{2 b(b r-\alpha)(a r-\alpha c)-(b r-\alpha)^{2}(b c+a)}{2 b(b r-\alpha)^{2}+8 b^{2}(\alpha r-\beta)} \\
\theta_{d}^{*}=[(b r-\alpha)(b c+a)+2 b(\alpha c-a r)] /\left[(b r-\alpha)^{2}+4 b(\alpha r-\beta)\right] \\
p_{d}^{*}=\frac{b c+3 a}{4 b}+\frac{(3 \alpha-b r)(b r-\alpha)(b c+a)+\left(2 b^{2} r-6 \alpha b\right)(a r-\alpha c)}{4 b(b r-\alpha)^{2}+16 b^{2}(\alpha r-\beta)}
\end{gathered}
$$

By introducing the function of optimal solution (4)-(6) into function (1), (2), the profit of retailer, manufacturer and supply chain under the decentralized decision mode can be obtained, they are $\pi_{r}, \pi_{m}, \pi_{s c}$

\subsection{Decisions by Retailers and Manufacturers under the Centralized Decision-Making Model}

In the centralized decision-making mode, retailers and manufacturers make joint decisions as a whole, and decide green degree and retail price of green products at the same time in order to maximize the profit of supply chain. At this point, the overall profit function of the supply chain is:

$$
\pi_{s c}=(p-c+r \theta) D-\beta \theta^{2} / 2=(p-c+r \theta)(a-b p+\alpha \theta)-\beta \theta^{2} / 2
$$

In the same way, we can find the first derivative of $p$ and $\theta$ of function (9) and make it zero. The optimal pricing decision of the supply chain is as follows:

$$
\begin{gathered}
p_{c}^{*}=\frac{a+b c}{2 b}-\frac{(b r-\alpha)^{2}(a+b c)+2 b(b r-\alpha)(\alpha c-a r)}{2 b(b r-\alpha)^{2}+4 b^{2}(2 \alpha r-\beta)} \\
\theta_{c}^{*}=[(b r-\alpha)(a+b c)+2 b(\alpha c-a r)] /\left[(b r-\alpha)^{2}+2 b(2 \alpha r-\beta)\right]
\end{gathered}
$$

Bring the function of optimal solution (8) and (9) into function (7), we can get the total profit of the supply chain under the centralized decision mode.

According to the calculation results, the optimal green degree of products made by manufacturers is higher than that of decentralized decision model, and the retail price of product is higher than that of decentralized decision model under the centralized decision model. The overall profit of supply chain under decentralized decision is lower than that of supply chain under centralized decision. This means that the supply chain does not reach the Pareto optimal state under the decentralized decision. This paper discusses the design of the contract mechanism for the decentralized decision to realize the Pareto improvement of 
the supply chain.

\section{Design of Supply Chain Coordination Mechanism}

According to the previous analysis, the supply chain can obtain higher overall profits under the centralized decision-making mode. In this section, a sharing contract of supply chain revenue is designed to coordinate the supply chain revenue under the decentralized decision-making mode. Supply chain revenue-sharing contract is divided into two stages: firstly, the manufacturer determines the wholesale price of green products to the retailer, and then the retailer provides the manufacturer with a certain share of income as compensation, expressed by symbol $F$.

In this case, the retailer and manufacturer's profit function are:

$$
\begin{gathered}
\pi_{r}^{c}=(p-w)(a-b p+\alpha \theta)-F \\
\pi_{m}^{c}=(w-c+r \theta)(a-b p+\alpha \theta)-\beta \theta^{2} / 2+F
\end{gathered}
$$

When the supply chain is coordinated by revenue-sharing contract, the optimal green degree and retail price of green product should be consistent with the optimal decision result under the centralized decision. By introducing function (8) and (9), the optimal green degree and the retail price of the above green product, into the above function, the optimal retail price of the manufacturer can be obtained, which is as follows:

$$
w^{c}=\left[b c r \alpha-2 b c \beta+2 b r^{2}+c \alpha^{2}+a \alpha r\right] /\left[(b r-\alpha)^{2}+2 b(2 \alpha r-\beta)\right]
$$

According to the results of the calculation, we get $w^{c} \leq w_{d}^{*} \leq p_{d}^{*}$. This shows that, if there is no profit-sharing $F$ between retailers and manufacturers in the contract, the retailer can gain higher profits, and the manufacturer will lose certain profit compared with decentralized decision-making mode. So, the contract design of benefit sharing $F$ is very important.

Assuming that the manufacturer and retailer's acceptable minimum retained profits are $\pi_{m}^{0}$ and $\pi_{r}^{0}$ respectively, the manufacturer is willing to accept the contract only if $F$ satisfies $\pi_{m}^{c} \geq \pi_{m}^{0}$, that is

$$
F \geq F_{1}=\pi_{m}^{0}-\left(w^{C}-c+r \theta_{C}^{*}\right)\left(a-b p_{C}^{*}+\alpha \theta_{C}^{*}\right)-\beta \theta_{C}^{* 2} / 2
$$

Only if F meets $\pi_{r}^{c} \geq \pi_{r}^{0}$, the retailer is willing to accept the contract, that is

$$
F \leq F_{2}=\left(p_{C}^{*}-w^{C}\right)\left(a-b p_{C}^{*}+\alpha \theta_{C}^{*}\right)-\pi_{r}^{0}
$$

\section{Numerical Experiments}

After the previous analysis, this study has reached some conclusions. This section will introduce specific numerical experiments to verify the conclusions. According to the study of Swami (2013) [14], the relevant parameters are set as $a=100$, $\mathrm{b}=6, \mathrm{c}=25, \mathrm{r}=5, \beta=5$.

The optimal green degree of green product under two decision modes can be 
obtained by adding the parameter value into the above optimal decision results and using the software to draw figures, which is shown in Figure 1. The optimal retail price of green product, and the wholesale price of it under the decentralized decision model and the centralized decision model in contract mechanism are shown in Figure 2. The overall profit of manufacturers, retailers and supply chains under decentralized decision mode and the profit of supply chain under centralized decision mode are shown in Figure 3.

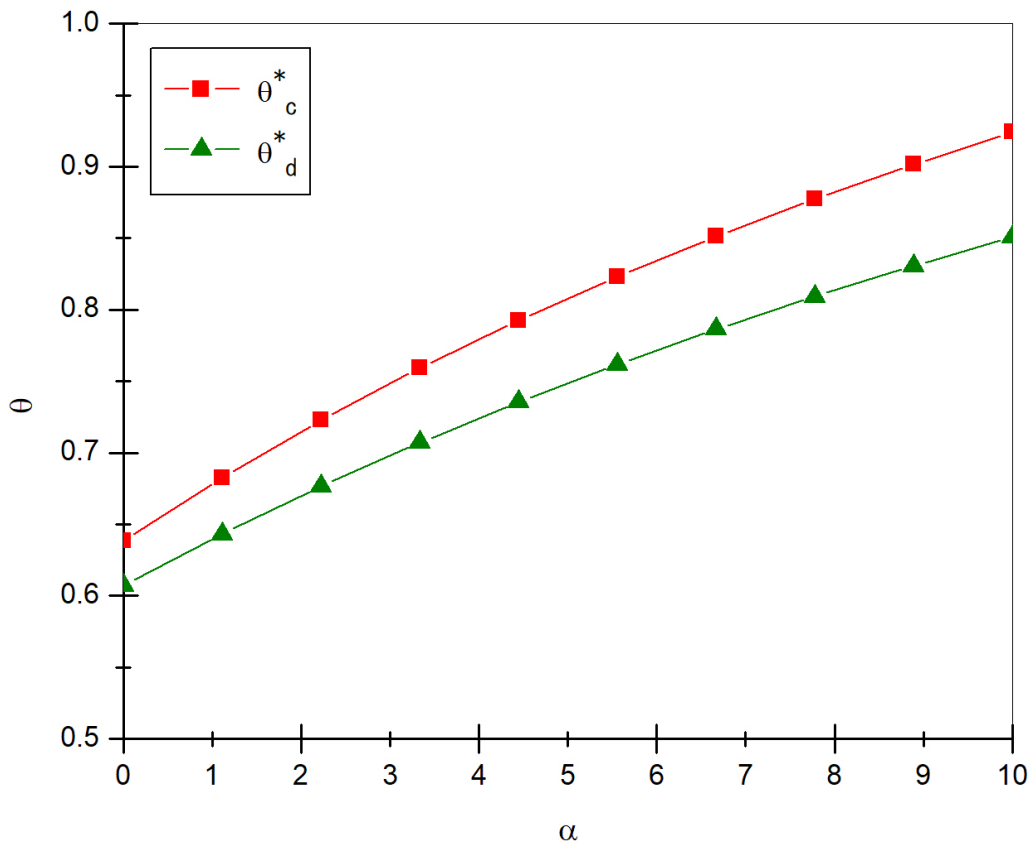

Figure 1. Optimal green degree decision of manufacturer green product.

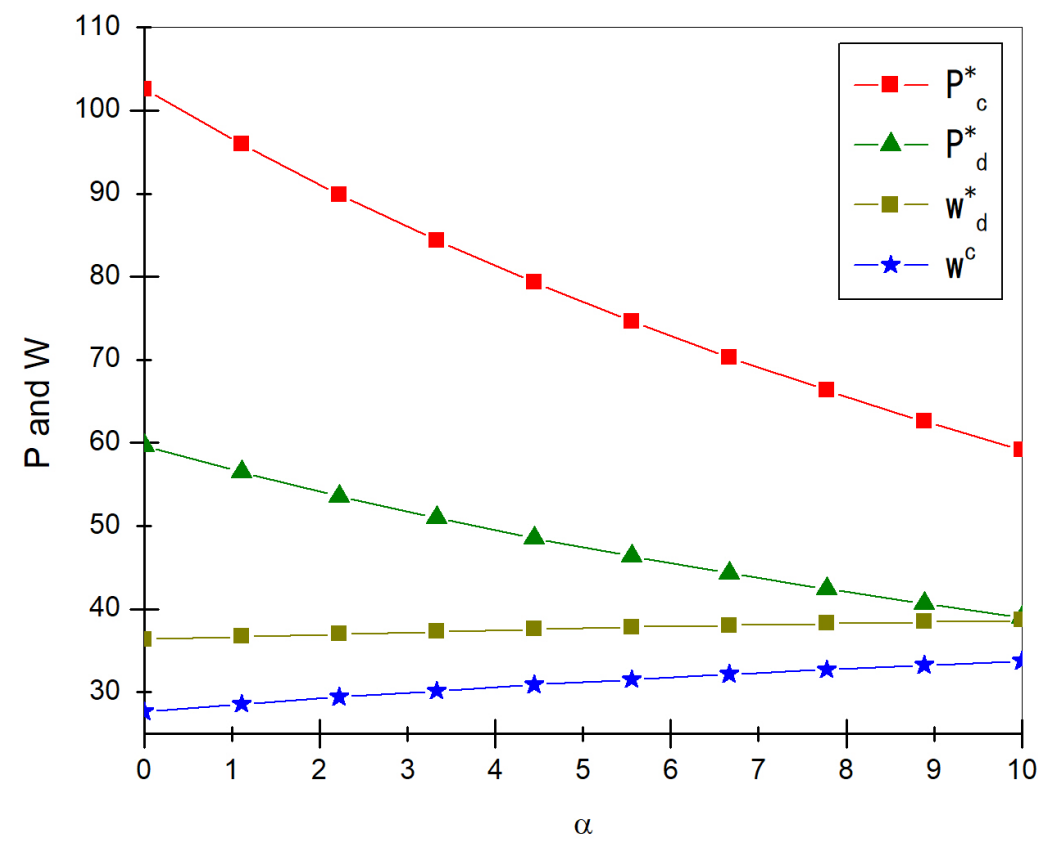

Figure 2. Optimal retail price and wholesale price decision. 


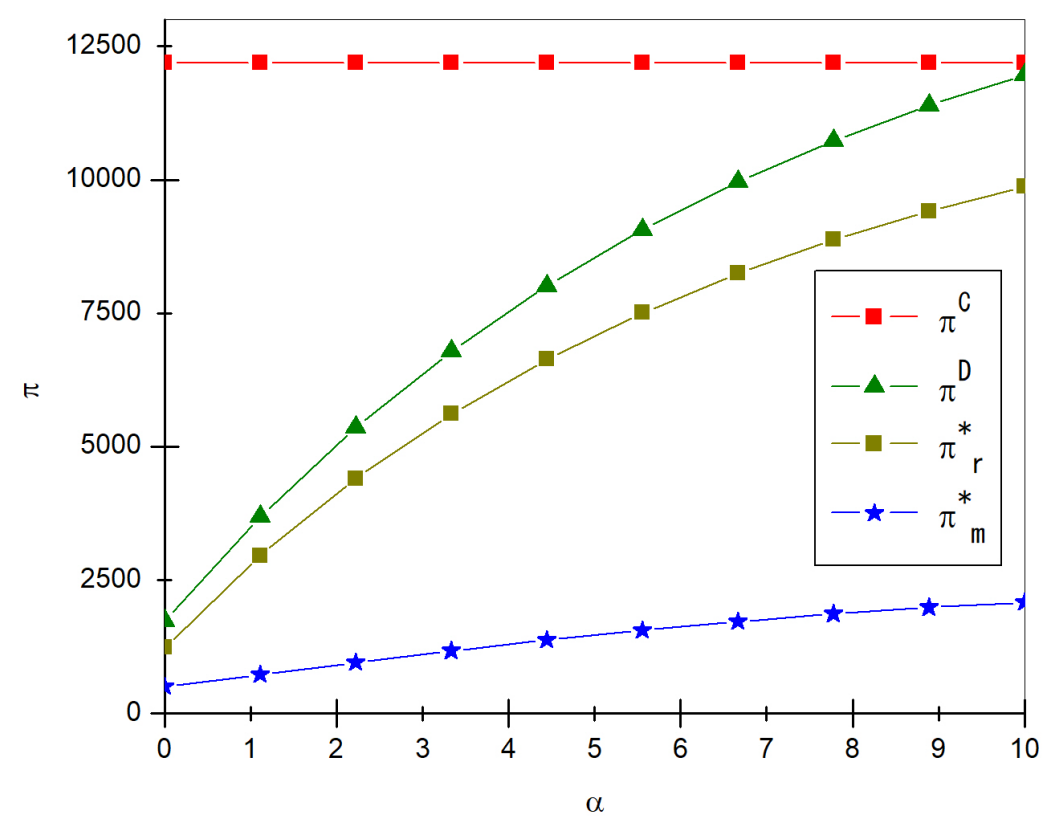

Figure 3. Profits of manufacturers, retailers and supply chain.

Figure 1 shows that under the centralized decision mode, the green degree of product under the manufacturer's decision is higher than that of the decentralized decision. The reason is that the supply chain is as a whole in the centralized decision-making mode, which can Offer products with a higher degree of greenery, and is more likely to stimulate consumer's demand and thus generate higher profits. In the same mode, the optimal green degree of the product made by the manufacturer will increase with the exaltation of the green sensitivity of the consumer, because the higher the sensitivity of the green product, the more willing to pay for the green product. Manufacturers can significantly increase the green product sales and their own profits by increasing the green degree of their products. On the whole, the green degree of the products made by the manufacturer is always above 0.6 , which indicates that although the optimal green degree will be different in different modes, the introduction of high-degree green products is the consensus of all parties in the market supply chain.

Figure 2 shows that the optimal retail price of products under centralized decision mode is always higher than that of decentralized decision mode, and in their respective mode, the optimal retail price will decrease with the increase of green sensitivity of consumers, which is because, the higher the green sensitivity of consumers, the more willing to buy. At this time, retailers reduce the retail price of products properly, the greater market demand can be caused and thus a higher level of profits can be achieved. Under the decentralized decision mode, the wholesale price set by manufacturers increases slowly with the increase of green sensitivity of consumers, which indicates that a win-win situation for manufacturers and retailers can be achieved if manufacturers tend to give more profits to retailers so as to promote retailers to reduce sales prices under the situation of consumers are more willing to pay for green products. In addition, 
under the coordination between decentralized decision model of supply chain and contract mechanism, the wholesale price set by the manufacturer is lower than that without the contract, which is because in order to achieve supply chain coordination, the retailer has to pay the manufacturer a sum of compensation. At the same time, manufacturers will also reduce wholesale prices accordingly to achieve the optimal overall profit in the supply chain.

Figure 3 shows that in decentralized decision-making mode, manufacturers and retailers can increase their respective profits rapidly as consumers' green sensitivity increases, and retailers' profits are always higher than manufacturers'. Under the centralized decision-making mode, the overall profit of the supply chain is relatively stable, and with the increase of green sensitivity of consumers, there is only a minimal decline. This is because in the centralized decision-making mode, supply chain as a whole tends to set a higher retail price, regardless of the green sensitivity of consumers, can achieve a higher level of profit, and with the continuing reduction of pricing, the overall profit of the supply chain will also decline slightly. In addition, the overall profit of supply chain in centralized decision-making mode is always higher than that in decentralized mode.

\section{Conclusions and Directions for Future Research}

Based on the background of government subsidizing green products, this paper establishes a two-level green product supply chain decision model composed of manufacturers and retailers. The optimal decision behavior of manufacturer and retailer under the two decision modes of decentralization and centralization is analyzed, and the contract mechanism to realize the coordination of supply chain is also analyzed. The findings are as follows.

First, in the decentralized decision-making mode, manufacturers, as supply chain leaders, tend to produce higher green products and set higher wholesale prices, while, retailers tend to set higher retail prices to make profits. The overall profit of the supply chain is not superior to the centralized decision model.

Second, the design of contract mechanism can solve the problem of uncoordinated decision of supply chain in decentralized decision-making mode, and realize the win-win solution between manufacturer and retailer, but it needs the participation and negotiation of manufacturer and retailer.

Third, government subsidies are conducive to promoting the promotion of green products, but the final effect is also related to consumers' willingness to pay for green products. The higher the green sensitivity of consumers, the more conducive to the green product input of manufacturers. Retailers are also more inclined to reduce retail prices, and the profit of the supply chain will vary according to the different decision models.

This article researches the issue of green supply chain decision-making and coordination in the background of government subsidies, and complements the lack of research in this area. However, this article only considers the situation of single green product manufacturers and single retailers. In the future, it could be 
extended to multiple manufacturers and retailers. In addition, it is also meaningful to research the situation that both green products and common products exist, and the situation that different subsidy modes exist in the market.

\section{References}

[1] Menges, R. (2003) Supporting Renewable Energy on Liberalized Markets: Green Electricity between Additionality and Consumer Sovereignty. Energy Policy, 7, 583-596. https://doi.org/10.1016/S0301-4215(02)00144-1

[2] Bowen, F.E., Cousins, P.D., Lamming, R.C., et al. (2001) The Role of Supply Management Capabilities in Green Supply. Production and Operations Management, 10, 174-189. https://doi.org/10.1111/j.1937-5956.2001.tb00077.x

[3] Li, Y.N. and Ye, F. (2011) Institutional Pressures, Environmental Innovation Practices and Firm Performance-An Institutional Theory and Ecological Modernization Theory Perspective. Studies in Science of Science, 29, 1884-1894.

[4] Eriksson, C. (2004) Can Green Consumerism Replace Environmental Regulation? A Differentiated-Products Example. Resource and Energy Economics, 3, 281-293. https://doi.org/10.1016/j.reseneeco.2003.10.001

[5] Zhu, Q.H. and Dou, Y.J. (2007) An Evolutionary Model between Governments and Core-Enterprises in Green Supply Chains. Systems Engineering Theory and Practice, 12, 85-89.

[6] Cohen, M.C., Lobel, R. and Perakis, G. (2015) The Impact of Demand Uncertainty on Consumer Subsidies for Green Technology Adoption. Management Science, 9, $1-24$.

[7] Conrad, K. (2005) Price Competition and Product Differentiation When Consumers Care for the Environment. Environment and Resource Economics, 31, 1-19. https://doi.org/10.1007/s10640-004-6977-8

[8] Liu, Z., Anderson, T.D. and Cruz, J.M. (2012) Consumer Environmental Awareness and Competition in Two-Stage Supply Chains. European Journal of Operational Research, 218, 602-613. https://doi.org/10.1016/j.ejor.2011.11.027

[9] Zhang, L.H., Wang, J.G. and You, J.X. (2015) Consumer Environmental Awareness and Channel Coordination with Two Substitutable Products. European Journal of Operational Research, 241, 63-73. https://doi.org/10.1016/j.ejor.2014.07.043

[10] Mitra, S. and Webster, S. (2008) Competition in Remanufacturing and the Effect of Government Subsidies. International Journal of Production Economics, 111, 287-298. https://doi.org/10.1016/j.ijpe.2007.02.042

[11] Cohen, M.C., Perakis, G. and Thraves, C. (2015) Competition and Externalities in Green Technology Adoption. Working Paper. Massachusetts Institute of Technology, Cambridge. https://doi.org/10.2139/ssrn.2607688

[12] Ling, L.Y., Dong, H.X. and Liang, L. (2012) Analysis of Monopoly Market for Green Products from the Perspective of Government Subsidies. Operations Research and Management Science, 21, 139-144.

[13] Savaskan, R.C. and Van Wassenhove, L.N. (2006) Reverse Channel Design: The Case of Competing Retailers. Management Science, 52, 1-14. https://doi.org/10.1287/mnsc.1050.0454

[14] Swami, S. and Shah, J. (2013) Channel Coordination in Green Supply Chain Management. Journal of the Operational Research Society, 64, 336-351. https://doi.org/10.1057/jors.2012.44 